\title{
What Is Preparedness and Capacity of Intensive Care Service in Indonesia to Response to COVID-19? A Mixed-method Study
}

\author{
Mochamat Helmi ${ }^{1 *}$ (i), Djayanti Sari ${ }^{2} \mathbb{D}$, Andreasta Meliala ${ }^{3} \mathbb{D}$, Laksono Trisnantoro ${ }^{3} \mathbb{D}$ \\ ${ }^{1}$ Department of Anesthesiology, Faculty of Medicine, Universitas Tarumanagara, Jakarta, Indonesia; ${ }^{2}$ Department of \\ Anesthesiology and Intensive Care, Faculty of Medicine, Public Health and Nursing, Universitas Gadjah Mada, Jogjakarta, \\ Indonesia; ${ }^{3}$ Department of Health Policy and Management, Faculty of Medicine, Public Health and Nursing, Universitas Gadjah \\ Mada, Jogjakarta, Indonesia
}

Edited by: Mirko Spirosk Citation: Helmi M, Sari D, Meliala A, Trisnantoro L. What Is Preparedness and Capacity of Intensive Care Service Study Open Access Maced J Med Sci. 2021 . S(B):1686-1694.https://doi.org/10.3889/oamjms.2021.7626 Keywords: Coronavirus disease 2019; COVID-19; Preparedness; Capacity; Intensive care service *Correspondence: Mochamat Helmi, Departmen of Anesthesiology, Faculty of Medicine, Universitas Tarumanagara, Jakarta, Indonesia. E-mail: helmi@yahoo.com Received: 17-Oct-202 Accepted: 03-Dec-2021 Copyright: @ 2021 Mochamat Helmi, Djayanti Sari, Andreasta Meliala, Laksono Trisnantoro Funding: This research did not receive any financia Competing Interests: The authors have declared that no competing interests exis Open Access: This is an open-access article distributed under the terms of the Creative Commons Attribution-

\begin{abstract}
BACKGROUND: Pandemics can increase disease spread, as well as unpredictable and highly in patient demand which can have a negative impact on hospital capacity and the overall functioning of the health-care system. The preparedness and capacity of intensive care services to respond to COVID-19 in Indonesia are remain unknown.
\end{abstract}

AIM: This study aimed to investigate the preparedness and capacity of intensive care services in Indonesia to respond to the initial stage of the COVID-19 pandemic.

METHODS: A mixed-method research design was used in this study using in-depth interviews and an online survey. An in-depth interview was conducted with the medical team (intensive care consultant and an anesthesiologist) who is actively involved in the provision of COVID-19 services in 15 national referral hospitals. The online survey was conducted to all medical teams that provide direct care to the COVID-19 patients. A total of 459 (response rate was $95.2 \%$ ) agreed to join the survey. The content analysis technique was used to analyze qualitative data and a descriptive analysis was used to describe issues encountered in providing health services to COVID-19 patients.

RESULTS: The analysis preparedness and capacity of intensive care service in Indonesia to respond to the initial stage of the COVID-19 pandemic resulting in 4 themes with 12 sub-themes. The four themes were limited quality and quantity of standardized intensive care unit (ICU) isolation room (inadequate zoning systems, adequacy of the standardized ICU isolation room, the readiness of the hospital infrastructure, and telemedicine facilities are not yet widely used, including in the COVID-19 isolation room), limited medical service support (lack of personal protective equipment (personal protective equipment [PPE], re-used PPE, lack of availability of medical devices), limitations in the medical team's quality and quantity management (lack of number and distribution of expert doctors and medical team screening for ICU), and command systems (task shifting, effective communication, and leadership).

CONCLUSION: Medical team encounters several difficulties, particularly related to the quality of facilities, staff preparedness, and systems for the provision of services to COVID-19 patients with critical conditions. There is a critical need for well-defined pathways, legal protection, and occupational health for medical teams providing services in the aftermath of a pandemic.

\section{Introduction}

COVID-19 was declared as a pandemic by the World Health Organization (WHO) on March 12, 2020 [1], [2]. As of May 1, 2020, (4 months of COVID-19 cases worldwide), 3,337,826 people worldwide were infected with COVID-19; 235,577 deaths and 1,054,833 declared cured of this disease [2]. About $5-16 \%$ of patients confirmed with COVID-19 require admission to intensive care units (ICUs) [3]. There is an alarmingly high rate of ICU mortality (62\%) over 28 days [4], higher than that of serious ARDS [5]. Indonesia confirmed the first two COVID-19 cases on March 2, 2020, and then the new cases of COVID-19 infection are increasing every day significantly. Within 2 months, more than 10,500 new cases were found in all provinces in Indonesia, resulting in no single Green Zone Province in Indonesia (an area without infection cases). COVID-19 was declared a national disaster by the Indonesian government on March 14, 2020 [6].

Hospitals play a pivotal role to provide healthcare services to people, especially during natural or manmade catastrophic events. Pandemics can increase disease spread, as well as unpredictable and highly in patient demand, which can have a negative impact on hospital capacity and the overall functioning of the healthcare system. Hospitals must have managed to complete their preparedness before these events occur to deal with the complexity of dealing with an epidemic disaster. In a condition where the number of patients is higher than service capacity, several strategies need to be considered to overcome it, such as space (infrastructure), stuff (tools and logistics), staff, and systems (4S), which must consider all services from patient admission to discharge from hospitals, including intensive care services [7], [8].

The ICU will be simultaneously challenged on multiple fronts. These include resource limitations, infection 
control, protection of healthcare workers, and adaptation of services to a rapidly evolving pandemic situation [3]. The availability of isolated ICU is one of the primary resource constraints that may limit COVID-19 patient services. At present, few hospitals have adequate isolation rooms, especially to receive COVID-19 patients [9]. Hospital isolation in Indonesia, including those fitted with negative pressure, anteroom rooms, and contaminated spaces, does not follow infection prevention and control (PPI) guidelines [6]. Furthermore, the intensive care service system must be adjusted to COVID-19 conditions, which includes changes to all phases of service, including determining eligibility for ICU care to ICU triage, screening for disease severity, initial assessment and reassessment, and isolation-related care [7].

Medical equipment supplies, including medications and disposables, as well as equipment that supports respiration management and personal protective equipment (PPE), must be properly maintained. PPE and ventilator machines are very important logistical roles, especially for COVID-19 patients [7], [9]. In addition, ventilator machines are another important concern, as most hospitals do not reserve all of their ventilators exclusively for COVID-19 patients, assuming the hospital continues to accept non-COVID-19 patients [9], [10]. Thus, the hospital employs a special allocation policy to prevent transmission related to ventilators, even the risk management is unknown certainty. The limited number of personnel in the ICU must be considered in preparation, both in number and in quality. The service of COVID patients in the ICU faces several challenges at first since not all medical staff is willing or deserving of providing services to this patient population [7], [10]. There are several reasons why medical staff is willing to provide services to patients with COVID-19, including psychological factors, age, comorbidity, knowledge, and personal protection. Worrying about contracting and transmitting the disease to your closest relatives is one of the psychological factors. This anxiety is found in more than half $(56.7 \%)$ of health workers who are not familiar with the pandemic [11], [12]

The preparedness and capacity of intensive care services to respond to COVID-19 in Indonesia are remain unknown. To inform policy and appropriate and timely responses, this study aimed to investigate the preparedness and capacity of intensive care service in Indonesia to respond to the initial stage of the COVID-19 pandemic.

\section{Methods}

\section{Study design}

A mixed-method research design was used in this study using in-depth interviews and an online survey. An in-depth interview was conducted virtually with the medical team who provide direct care to COVID-19 patients with critical condition from July 19 to August 14, 2020. Then, an online survey using Google form was distributed randomly through social media to all medical personnel who directly cared for COVID-19 patients in critical condition. This survey was perfume from August 23 to September 18, 2020. This survey aimed to identify the issues encountered in providing health services to COVID-19 patients in terms of the four aspects (space, staff, staff, and systems) at the ICU in Indonesia.

\section{Participants}

An in-depth interview was conducted with the medical team (intensive care consultant and an anesthesiologist) who is actively involved in the provision of COVID-19 services in 15 national referral hospitals. A total of 58 participants agreed to join in this study, including 13 intensive care consultants and 45 anesthesiologists. They were 31 males and 27 females, with a mean age of 38.53 years $(S D=8.54)$. Participants in this interview were then assigned the codes 1.2.1 to 1.2.45. An online survey was conducted to all medical teams that provide direct care to the COVID-19 patients. A total of 459 (response rate was $95.2 \%$ ) agreed to join the survey. About $34.64 \%$ were general practitioners, $26.58 \%$ internship, and $11.55 \%$ anesthesiologist and distributed in all 34 provinces in Indonesia.

\section{Measures \\ Interview guideline}

The interview guide was developed by researchers after conducting a literature review and consulting with experts. This interview guide is then validated to ensure that the interview direction is consistent with the research goals. Interviews were conducted using semi-structured interview techniques and included general questions such as the following: (1) How are you preparing as a medical team to deal with COVID-19 patients, especially if there is a surge in cases? (2) How can the hospital be able to handle COVID-19 concerning its space, stuff, personnel, and systems? (3) What do you think of COVID-19's availability of space, stuff, staff, and systems? While focus group discussion focused on the expert opinion about government policy toward COVID-19 surge capacity.

\section{$4 S$ working environment assessment}

$4 \mathrm{~S}$ working environment assessment is a self-developed instrument aimed to measure 
the working condition experienced by the medical team, including space, stuff, stuff, and systems. The developed instrument consists of 50 questions with four domains included in the structure and process indicators, which are as follows: There are ten questions about space, eight questions about stuff, 16 questions about staff, and 19 questions about systems. This instrument is a Likert scale with response options ranging from 1 to 5 . One indicates strong disagreement, two indicates disagreement, three indicates neutrality, four indicates agreement, and five indicates strong agreement. High scores suggest that perception and practice are very good. The validity test results obtained a Root Mean Square Error of Approximation value of 0.063 with a probability of $0.05-0.088$, indicating that the model is fitted with the factor loading of each item ranging from 0.60 to 0.71 . With the reliability range of $0.59-0.73$, all-composite reliability was declared reliable.

\section{Procedure}

This study was approved by the institutional review board of the affiliated university (No. KE/ FK/0742/EC/2020). The participants were provided a full overall description and procedure of the study before actually conducting data collection, and those interested in taking part voluntarily were requested to fill the written consent form. They were provided a description that the information gathered would be used for the research purpose and coded to protect personal information. The interview was conducted with qualitative analysis; it took them 40-50 min to complete the interview. The data were audiotaped with a tape recorder and subsequently transcribed with the consent of the respondents. Google collected confidential information on the online survey during the whole process. The data are then saved on a drive that only the research team has access to. The system automatically eliminated the possibility of double respondents by preventing two or more users from the same e-mail address from accessing the study after the questionnaire was completed. The data were transformed into a codebook.

\section{Data analysis}

The content analysis technique developed by [13] was used to analyze qualitative data. The themes, categories, and codes were compared for similarity and dissimilarity. Participants were given a simplified version of the interviews to verify the researchers' interpretation of the data. Peer review was requested to ensure the data were accurate. A group of faculty and clinical experts have reviewed all coded data and categories several times during the analytical process for audibility. A descriptive analysis was conducted to describe issues encountered in providing health services to COVID-19 patients in terms of the four aspects (space, stuff, staff, and systems) at the ICU in Indonesia.

\section{Results}

The analysis preparedness and capacity of intensive care service in Indonesia to respond to the initial stage of the COVID-19 pandemic resulting in four themes with 12 sub-themes. The four themes were limited quality and quantity of standardized ICU isolation room, limited medical service support, limitations in the medical team's quality and quantity management, and command systems.

\section{Theme 1: Limited quality and quantity of standardized ICU isolation rooms}

The data review immediately highlights the limited availability and quality of standardized ICU COVID-19 isolation rooms. This is an issue that arises when it comes to infrastructure.

\section{Inadequate zoning systems}

There were still crossovers between indoor zones such as access and exit channels for patients and medical staff, sites for installing and removing PPE, and chambers with negative pressure in the COVID-19 ICU room.

"...How to organize the patient flow, where the patient comes from, where the staff comes from, where he has to doff, where he donates, where the red area is, where the yellow area is, where the green area is, where he has to bathe, and all sorts. Indeed, my experience has been, and this is purely subjective, that the question is typically something along those lines, the division of the area..." (2) (1.2.2)

"...The area's division has not been detailed yet. Whereas, if there is a distinct distinction of zones, uncontrolled exposure can be reduced..." (1.1.2.)

In the online survey, there were 25 data (114 out of 459 respondents) reported that the zoning system was not determined by the hospital where they worked. Only $18 \%$ of the medical team acknowledged using anteroom as an intermediary place to reduce contamination between the isolation room and the cleaning room.

\section{Adequacy of standardized ICU isolation room}

The adequacy of standardized ICU isolation rooms became an initial problem related to COVID-19 
services with critical conditions according to the medical team's assessment. According to the findings of this study, the planning for an increase in patient service capacity at the start of the pandemic was deemed insufficient, particularly in terms of being able to prepare for situations when the number of patients exceeded the number of capacities available. Interviews with representatives of anesthesia specialists at 15 national referral hospitals for COVID-19 revealed that at the beginning of the COVID-19 pandemic, there was still a sufficient ratio of anesthesia specialists to the number of patient beds allocated.

"So far, it has been sufficient; this means that the current patient load and bed availability are being met, but we must still prepare for worst-case scenarios." (1.2.11)

"In my position, I am on the verge of crossing the border, as there has been a significant increase in cases over the last few weeks, and we must develop a strategy and plan carefully to overcome the ICU's unrestricted rooms and bedrooms." (1.2.7.)

The availability of critical beds is on average 15 beds (SD $=3.04$ ) and approximately $50 \%$ of the total critical beds have been used for COVID-19 patients. Furthermore, the anesthesia specialist and consultant ratios with the number of beds in each hospital were obtained. For example, eight referral hospitals in Indonesia have extremely high ratios of $5: 15$, while the other five hospitals have enough ratio of $3: 1$, and two hospitals did not have anesthesia specialists and consultants.

\section{Readiness of the hospital infrastructure}

Data from the interview revealed that the hospital was not prepared to deal with the increased COVID-19 case, particularly in ICU rooms with limitedservice support facilities.

"I believe that nearly all of the ICU rooms have limitations and could be considered unprepared and that if there is a significant increase in cases, it is necessary to seriously consider how, for example, converting another room into an ICU room, which of course requires a tremendous amount of money." (1.2.2.)

"Yes, in my opinion, we are not ready from room capacity and other support facilities." (1.2.13)

According to the findings of an online survey, $96 \%(n=459)$ of respondents stated that the hospital where they worked did not have adequate infrastructure to safely handle the surge in COVID-19 with critical condition. Only $25 \%$ ( $n=114$ ) had enough bed capacity, $33 \%$ had a zoning system and anteroom, only $18 \%$ reported that all ICU having negative pressure, and $24 \%$ used CCVT.
Telemedicine facilities are not yet widely used, including in the COVID-19 isolation room

The fourth dimension of this theme is the insufficient use of remote patient monitoring facilities such as closed-circuit television (CCTV) and telemedicine systems, which include the COVID-19 isolation room. The informant stated that the use of CCTV and telemedicine could assist the Medical Team in providing services to patients. The use of CCTV may help to reduce the risk of exposure to the medical team and dividing up areas that are not yet detailed. Furthermore, the medical team is not required to monitor patients near the patient, as monitoring can be done in an integrated manner using a monitor that shows the vital signs of the patient, including a picture of the patient's current condition. Only $24 \%(n=15)$ of hospitals used CCTV and only 13 hospitals used facilities to be able to monitor the condition of patients remotely.

"...Even though using media to monitor isolation patients will assist minimize the duration and unnecessary workload, it has not been adopted consistently." (1.2.2.)

"Monitoring isolated patients by asking questions through the app might sometimes be beneficial. However, it is unclear how the limitations and implementation will be determined." (1.1.11)

"...Similarly, in the hospital where I work, telemonitoring has not been fully implemented, particularly for COVID-19 patients in the ICU." (1.2.17)

\section{Theme 2: Limited medical service support}

\section{Lack of PPE}

The first dimension, a shortage of PPE, occurred during the COVID-19 pandemic early stages. Informants believe the PPE shortage is a big problem where they work; this is supported by various expressions:

"The explanation is safe for the patient and how it is safe for us, in particular against PPE's limitations." (1.2.16)

“...Particularly where the PPE is limited, and so what a good thing is PPE, we are going to use it later, as if it is still safe" (1.2.7)

"There has been a lack of PPE in the medical team, both in terms of physical protection and knowledge of how to use it. This made growing worries." (1.2.12)

Quantitative research indicates that several hospitals lack access to PPE such as Google's, face shields, and gowns. About $90 \%$ of respondents reported limited on N95 mask, $84 \%$ hazmat, $45 \%$ face shield, $55 \%$ head cap, and $63 \%$ boots.

The safety of the medical team to provide services for COVID-19 patients with critical conditions is not limited 
solely by the preservation of the number and quality of PPE used. Keeping PPE safe during the assignment, as well as being able to remove PPE in the correct manner/ method and the appropriate order of release, is very important knowledge to be applied correctly.

"If PPE has limitations, then what good is it; later on, we will use it with whatever we can get" (1.2.10)

"We still do not understand how the protection should be applied when taking action, such as what is best for those who are modest but safe, which is what they need to know." (1.2.7)

\section{Re-used of PPE}

Furthermore, the lack of quality and quantity of standardized PPE demands the creation of health workers to reuse the used PPE. PPE with good quantity and quality greatly determines the safety of the medical team in carrying out its duties; hence, PPE should be prepared following the standards set by each health facility.

"The PPE standards have already been issued by the Ministry of Health, so how do all of the health facilities enforce the standards?" (1.2.4).

In the online survey, $30 \% \quad(\mathrm{n}=459)$ of respondents said they re-used Google, $24 \%$ re-used hazmat, $21 \%$ said they re-used face shield, and $12 \%$ re-used $\mathrm{N}-95$. This reuse process is not accompanied by good socialization; hence, the process required to re-use PPE could be a source of COVID-19 transmission to the medical team. According to the survey results, one-third of participants did not know how to re-use PPE and $58 \%$ of respondents stated that the quality of PPE reuse was not assessed.

\section{Lack of availability of medical devices}

Several hospitals were experiencing a shortage of ventilators and other medical devices to support the medical team's skills.

"...As a result, the phenomenon of a surge in patients at the start of the pandemic has an impact on fighting over a ventilator." (1.1.42)

"...Even though the document for device allocation has been completed, the acceptance will take a long time." (1.2.22.)

"No matter how you request tools to support health services, instruments that should be is missing." (1.2.17)

Hospitals should also be able to prepare medical devices and other medical supplies which support patient care and safety. A ventilator and a high flow nasal cannula (HFNC) are the most focused medical devices for the service of COVID-19 patients with critical conditions. According to the results of the online survey, $18 \%(n=459)$ of respondents had sufficient availability for a ventilator and $29 \%$ for HFNC.

Theme 3: Limitations in the medical team's quality and quantity management

\author{
Lack of number and distribution of expert \\ doctors
}

In Indonesia, there are many areas where experts are lacking/not available.

"In areas without expertise, plus poor-risk distribution. There are several hospitals in remote areas that lack anesthesiologists" (1.1.32)

Because the majority of referral hospitals are educational institutions, they frequently receive medical assistance for educational purposes. An online survey revealed that $27.8 \%$ of the hospital did not have a sufficient number of the medical team (to serve COVID19 patients in critical condition. This number will further decrease with a medical team exposed to COVID-19.

This deficiency is not only in quantity but also in quality in providing services to COVID-19 patients with critical conditions in terms of both knowledge and eligibility screening process. The medical team involved in the provision of COVID-19 patient services must go through a screening process, namely, the selection of a proper medical team (physically and mentally), qualified), and willing to provide services to patients.

\section{Medical team screening for ICU}

There is a lack of a good screening process for the medical team to be able to deliver services to COVID-19 patients in the ICU.

"...If he achieves more than the minimum, he can do the service, but sometimes it's not always done, depending on the requirements." (1.1.2)

This corresponds to the findings of an online survey, in which respondents emphasized the necessity of the medical team screening procedure before giving treatment to COVID-19 patients with critical conditions. It is also critical to screen administrative and other staff to keep non-patient care staff from coming into contact with the medical team. However, during the onset of the epidemic, the screening process was not done adequately. According to the survey, $37 \%$ of the medical team had access to rapid testing facilities, but only $33 \%$ had access to swab PCR regularly.

\section{Theme 4: Command system}

\section{Task shifting}

Command systematics is another important issue in health-care systems. Many areas with 
insufficient specialist doctors require task shifts and good coordination with hospitals with expert doctors as service providers.

"...The emergency is still a matter of minutes, so if later you have to wait for the long line of command, it means this will cause a delay, which may result in not only death but also the quality of life for the survivors." (1.2.12)

"...For the task-shifting issue, we have miscommunication. If our system does not actually work, and ultimately because it cannot be controlled, several hospitals have dealt with discharged patients for referral and release." (1.2.37)

\section{Effective communication}

Good communication is required for good coordination to provide appropriate task shifting.

"...Yes, good coordination is critical for this command. If this is accompanied with effective communication, it will be much better." (1.2.7).

"...So far, communication and coordination have been challenging. The reason for this is that twoway dialogues are ineffective when items are needed rapidly to make judgments." (1.2.5).

\section{Leadership}

Furthermore, this dimension includes the dimension of leadership or leadership. Good leadership may provide support for command system management, especially when dealing with crises, by providing data.

"... One more thing, leadership from the team leader is critical in the task-shifting system." (1.2.21)

"...Command has worked so far when the leader can demonstrate appropriate leadership characteristics." (1.2.16).

According to the survey results, $38 \%$ of respondents had difficulty referring patients. In addition, $89 \%$ of respondents reported having a COVID-19 team at their place of employment, but only $20 \%$ reported that the COVID-19 team formed could or was able to carry out its duties in assisting in the facilitation of COVID-19 services, including referral and command system.

\section{Discussion}

The purpose of this study is to assess the preparedness and capacity to provide services to COVID-19 patients with critical conditions among the medical team, particularly in preparing for surge capacity. Hospitals encounter several difficulties, particularly related to the quality of facilities, staff preparedness, and systems for the provision of services to COVID-19 patients with critical conditions. A disaster with a significant number of victims can cause a surge of incapacity, which can affect resource availability. This situation can occur in all forms of natural disasters, industrial accidents, terrorist attacks, and pandemics, all of which can lead to critical conditions for a very large number of victims/patients [14]. The response to the increase of demand can differ depending on the severity of the disaster. The COVID-19 pandemic requires all levels of health-care providers to coordinate well with the ultimate goal of developing the right system to provide quality service, even though there are problems with infrastructure in providing services to COVID-19 patients with critical conditions.

Surge capacity had not yet occurred in most of the COVID-19 National Referral Hospitals in Indonesia at the beginning of the pandemic. The COVID-19 pandemic has caused a surge in capacity in many countries worldwide. For example, a study conducted in Spain found that the COVID-19 pandemic resulted in a surge in ICU patients who quickly filled available ICU capacity. Four new intensive care units had to be opened to accommodate all new ICU admissions. Infrastructure, material allocations, and ICU personnel are among the management challenges [15]. Whereas the Australian study indicated that 175 intensive care units were prepared for the surge (with 2228 beds), the maximum increase would add 4258 additional intensive care beds (19\% increase) and 2631 invasive ventilators (120\% increase) [16]. To date, hospital surge capacity has been nearly immeasurable, and it has frequently had to deal with increasing limitations in terms of stuff, staff, and space. However, during times of extreme need, highly flexible, and adaptable management strategies can help overcome some of these limitations and stretch the system's capacity.

The study results reported a lack of hospital infrastructure preparedness to deal with the COVIC-19 pandemic and the potential for surge capacity. This is indicated by the limited quality and quantity of standardized ICU isolation rooms, unmanaged room zoning systems, and inadequate use of telemedicine facilities including in the COVID-19 isolation room. In general, the ICU should be completed and expanded immediately to at least $20 \%$ of its initial capacity [17]. Limited beds should be considered and anticipated under pandemic conditions. This condition was reported in several countries at the start of the pandemic, including Italy, Spain, and Australia [15], [16], [18]. Several studies also suggested mitigation schemes to prepare non-ICU areas for COVID-19 wards with critical conditions, while still considering COVID-19 PPI principles [15], [16]. The designation of an isolation ICU ward, geographically separate from other clinical areas, allows concentration and separation of equipment and staff, contributing to more effective efforts to prevent transmission. 
This study highlights the less utilization of telemedicine, even though the use of telemedicine was beneficial in terms of increasing work efficiency and reducing the risk of transmission [19], [20]. Telemedicine also helps to promote social distance and helps medical centers manage long waiting times and disease risk [21]. Virtual care solutions can help reduce virus transmission and protect medical practitioners from infection by minimizing direct visits and reducing face-to-face contact between doctors and patients [22]. Telemedicine and virtual care can play an important role in managing previous acute respiratory infections such as severe acute respiratory syndrome and the Middle East respiratory syndrome [23]. For example, the Australian government funds Medicare telemedicine services (Medicare home support) following COVID-19 and encourages doctors to provide health care [24]. Observing the success of the United States, China, and Australia in managing COVID-19 through telemedicine and virtual care, other countries such as Indonesia can also use telemedicine to fight this pandemic [24].

The findings of this study indicate that logistical readiness remains an issue, specifically a lack of support for personal protection and medical device availability (ventilators and other medical devices). At the beginning of the pandemic, national referral hospitals for COVID-19 in Indonesia still had relatively adequate logistics, even the quality was inadequate. Furthermore, due to the limited PPE available in the ICU, much medical personnel re-use various PPE items such as Google's, hazmat, and other items. This condition occurred in almost every country around the world, especially at the beginning of the COVID-19 pandemic [25], [26], [27]. In addition, the PPE kit must include features that ensure compliance, ease of procedure execution, thermal comfort (temperature and relative humidity), and the ability to breathe, while avoiding visual disturbances and problems associated with prolonged use, such as neck pain, back pain, and adverse skin reactions [28], [29], [30].

Human resources are the most critical component that must be considered and adequately prepared when managing COVID-19 patients in critical condition in the intensive care unit. The findings of this study highlight an important fact: There are insufficient numbers and distribution of doctors and specialists in many regions of Indonesia. The disparity in the number of specialists can raise concerns about the provision of adequate services in each hospital. Compared to the availability of medical teams, the number of the medical team identified in this study is much lower than in Australia and the United State, where almost all ICUs have a specialist or consultant intensive care [18], [31]. This study not only reveals a lack of quantity, but also a lack of staff quality. This is demonstrated by the inadequacy of the screening process used to determine which medical team is qualified to provide services. This screening process includes not only physical and mental issues but also readiness to provide services to critical ICU patients. To address this surge, it is important to develop a response for each hospital system to increase the ability to meet staff needs, one of which is relocating numbers. Several studies have described recommendations for increasing the number of ICU staff when there is a surge in demand, including certified anesthesiologists, intensive care unit nurses or anesthetic nurses (advanced practice providers), anesthesiologist specialist residents, general practitioners, and respiratory therapists [32].

Many areas with insufficient specialist doctors require task shifts and good coordination with hospitals that have expert doctors. The WHO outlines two strategies for expanding and ensuring access to essential health services through better utilization of existing health workers: Task shifting and task sharing [33]. Task shifting or task sharing enables the transfer of tasks from a high-quality medical team to a less-trained or less-qualified medical team, or the sharing of tasks with a medical team with the same qualifications. The use of available human resources in an overloaded health system is, therefore, more effective during the COVID-19 pandemic. The task shift process and an effective command system would then occur when supported by effective communication and leadership coordination. According to the WHO, effective communication and timely coordination are required to ensure informed risk assessment and decision-making, as well as effective collaboration, cooperation, and trust among all hospital staff and stakeholders. This includes communication and coordination within the hospital and through liaison with local and national authorities, including community and primary health services [2].

\section{Conclusion}

There have been several problems reported in COVID-19 service providers with critical conditions, includes: 1) Limited quality and quantity of standardized ICU COVID-19 isolation room, ineffective zoning systems, and limited telemedicine use, 2) lack of PPE and medical device availability (ventilators and other medical devices), 3) the number and distribution of expert doctors are not evenly distributed throughout Indonesia, there is a lack of a proper screening process for a proper medical team to provide services to COVID-19 patients in the ICU, and many medical teams who do not meet screening requirements are still required to assist care and administration, and 4) the command system including task shifting, effective communication, and leadership. Hospital management must develop a potential support team scheme to facilitate the transfer of responsibilities from a consultant in intensive care and anesthesiologists to general practitioners and residents, including recommendations on rights and responsibilities, 
health insurance, and clear and appropriate incentives for all types of professions who are involved in the intensive care of COVID-19. Professional associations should develop a technology-based command system scheme that incorporates the following components: communication and coordination, triage standards in the surge of capacity isolation rooms and intensive care units, end-of-life care, ethical and legal considerations, informed consent, and service recommendations. It is also deemed necessary to draft additional regulations relating to the license of medical teams in providing services, especially for volunteers. There is a critical need for well-defined pathways, legal protection, and occupational health for medical teams providing services in the aftermath of pandemic.

\section{Acknowledgment(s)}

We shall thank all COVID-19 medical team who worked in the hospital during the period of patient recruitment.

\section{Author Contributions Statement}

$\mathrm{MH}$ : Conceptualization (lead), data curation, formal analysis, funding acquisition investigation, project administration, validation, writing - original draft, writing review and editing. DS: Conceptualization, data curation, validation, writing - original draft, writing - review and editing. AM: Conceptualization, validation, visualization, writing - original draft, writing - review and editing. LT: Conceptualization (lead), validation, visualization, writing - original draft, writing - review and editing.

\section{Ethical Approval}

This study was approved by the institutional review board of the Universitas Gajah Mada (No. KE/ FK/0742/EC/2020).

\section{Data Availability Statement}

The datasets generated during and/or analyzed during the current study are available from the corresponding author on reasonable request.

\section{References}

1. Adhikari SP, Meng S, Wu YJ, Mao YP, Ye RX, Wang QZ, et al Epidemiology, causes, clinical manifestation and diagnosis, prevention and control of Coronavirus disease (COVID-19) during the early outbreak period: A scoping review. Infect Dis Poverty. 2020;9(1):29. https://doi.org/10.1186/s40249-020-00646-x PMid:32183901

2. World Health Organization. Coronavirus Disease (COVID-2019) Situation Reports. Geneva: World Health Organization; 2020. Available from: https://www.who.int/emergencies/diseases/ novel-coronavirus-2019/situation-reports [Last accessed on 2021 Aug 21].

3. Alhazzani W, Møller MH, Arabi YM, Loeb M, Gong MN, Fan E, et al. Surviving Sepsis Campaign: Guidelines on the management of critically ill adults with Coronavirus disease 2019 (COVID-19) Intensive Care Med. 2020;46(5):854-87. https://doi.org/10.1007/ s00134-020-06022-5

PMid:32222812

4. Yang X, Yu Y, Xu J, Shu H, Xia J, Liu H, et al. Clinical course and outcomes of critically ill patients with SARS-CoV-2 pneumonia in Wuhan, China: A single-centered, retrospective, observational study. Lancet Respir Med. 2020;8(5):475-81. https://doi. org/10.1016/S2213-2600(20)30079-5

PMid:32105632

5. Bellani G, Laffey JG, Pham T, Fan E, Brochard L, Esteban A et al. Epidemiology, patterns of care, and mortality for patients with acute respiratory distress syndrome in intensive care units in 50 countries. JAMA. 2016;315(8):788-800. https://doi. org/10.1001/jama.2016.0291

PMid:26903337

6. COVID-19 Task Force 2020. Gugus Tugas COVID-19. "Data Sebaran", Gugus Tugas Percepatan Penanganan COVID19; 2020. Available from: https://www.covid19.go.id/p/ regulasi/pp-no-21-tahun-2020-tentang-psbb-dalam-rangkapenanganan-covid-19 [Last accessed on 2021 Aug 21].

7. Liew MF, Siow WT, MacLaren G, See KC. Preparing for COVID-19: Early experience from an intensive care unit in Singapore. Crit Care. 2020;24(1):83. https://doi.org/10.1186/ s13054-020-2814-x

PMid:32151274

8. Medicine S. Recommendations for the admission of patients with COVID-19 to intensive care and intermediate care units (ICUs and IMCUs). Swiss Med Wkly. 2020;150:w20227. https:// doi.org/10.4414/smw.2020.20227

PMid:32208493

9. White D, Lo B. A framework for rationing ventilators and critical care beds during the COVID-19 pandemic. JAMA. 2020;323(18):1773-4. https://doi.org/10.1001/jama.2020.5046 PMid:32219367

10. Wujtewicz M, Dylczyk-Sommer A, Aszkiełowicz A, Zdanowski S, Piwowarczyk S, Owczuk R. COVID-19-what should anaethesiologists and intensivists know about it? Anaesthesiol Intensive Ther. 2020;52(1):34-41. https://doi.org/10.5114/ ait.2020.93756

PMid:32191830

11. Goulia P, Mantas C, Dimitroula D, Mantis D, Hyphantis T. General hospital staff worries, perceived sufficiency of information and associated psychological distress during the A/ H1N1 influenza pandemic. BMC Infect Dis. 2010;10:322. https:// doi.org/10.1186/1471-2334-10-322 PMid:21062471

12. Amour S, Djhehiche $K$, Zamora A, Bergeret $A$, Vanhems $P$. Perception of the $\mathrm{A} / \mathrm{H} 1 \mathrm{~N} 1$ influenza pandemic and acceptance 
of influenza vaccination by Université Claude Bernard Lyon 1 staff: A descriptive study. Hum Vaccin. 2015;11(3):727-31. https://doi.org/10.1080/21645515.2015.1008887

PMid:25715115

13. Graneheim UH, Lundman B. Qualitative content analysis in nursing research: Concepts, procedures and measures to achieve trustworthiness. Nurse Educ Today. 2004;24(2):105-12. https://doi.org/10.1016/j.nedt.2003.10.001 PMid:14769454

14. Sheikhbardsiri H, Yarmohammadian M, Khademipour G, Moradian M, Rastegarfar B, Rastegar M. An Operational exercise for disaster assessment and emergency preparedness in South of Iran. J Public Health Manag Pract. 2018;26(5):451-6. https://doi.org/10.1097/PHH.0000000000000815 PMid:32732718

15. Vena A, Giacobbe DR, di Biagio A, Mikulska M, Taramasso L, de Maria $A$, et al. Clinical characteristics, management and in-hospital mortality of patients with Coronavirus disease 2019 in Genoa, Italy. Clin Microbiol Infect. 2020;26(11):1537-44. https://doi.org/10.1016/j.cmi.2020.07.049

PMid:32810610

16. Carenzo L, Costantini E, Greco M, Barra FL, Rendiniello V, Mainetti $\mathrm{M}$, et al. Hospital surge capacity in a tertiary emergency referral centre during the COVID-19 outbreak in Italy. Anaesthesia. 2020;75(7):928-34. https://doi.org/10.1111/ anae. 15072

PMid:32246838

17. Hick J, Einav S, Hanfling D, Kissoon N, Dichter J, Devereaux A, et al. Surge capacity principles care of the critically $\mathrm{Ill}$ and injured during pandemics and disasters: CHEST consensus statement. Chest. 2014;146 Suppl 4:e1S-16S. https://doi.org/10.1378/chest.14-0733 PMid:25144334

18. Litton E, Bucci T, Chavan S, Ho Y, Holley A, Howard G, et al. Surge capacity of intensive care units in case of acute increase in demand caused by COVID-19 in Australia. Med J Aust. 2020;212(10):463-7. https://doi.org/10.5694/mja2.50596 PMid:32306408

19. Hau YS, Kim JK, Hur J, Chang MC. How about actively using telemedicine during the COVID-19 pandemic? J Med Syst. 2020;44(6):108. https://doi.org/10.1007/s10916-020-01580-z PMid:32350626

20. Tenforde AS, laccarino MA, Borgstrom H, Hefner JE, Silver J, Ahmed M, et al. Telemedicine during COVID-19 for outpatient sports and musculoskeletal medicine physicians. PM R. 2020;12(9):926-32. https://doi.org/10.1002/pmrj.12422 PMid:32424977

21. Dos Santos T. Teoria da Dependência: Balanço e Perspectivas. Português: Insular Livros; 2020.

22. Leung NH, Chu DK, Shiu EY, Chan KH, McDevitt JJ, Hau BJ, et al. Respiratory virus shedding in exhaled breath and efficacy of face masks. Nat Med. 2020;26(5):676-80. https://doi. org/10.1038/s41591-020-0843-2 PMid:32371934

23. Liu L, Wang EZ, Lee CC. Impact of the COVID-19 pandemic on the crude oil and stock markets in the US: A time-varying analysis. Energy Res Lett. 2020;1(1):13154.

24. Keshvardoost S, Bahaadinbeigy K, Fatehi F. Role of telehealth in the management of COVID-19: Lessons learned from previous SARS, MERS, and ebola outbreaks. Telemed J E Health. 2020;26(7):850-2. https://doi.org/10.1089/tmj.2020.0105 PMid:32329659

25. Bhattacharya P, Banerjee D, Tss R. The "Untold" side of COVID-19: Social stigma and its consequences in India. Indian J Psychol Med. 2020;42(4):382-6. https://doi.org/10.1177/0253717620935578 PMid:33402799

26. Rowan NJ, Laffey JG. Challenges and solutions for addressing critical shortage of supply chain for personal and protective equipment (PPE) arising from Coronavirus disease (COVID19) pandemic-case study from the Republic of Ireland. Sci Total Environ. 2020;725:138532. https://doi.org/10.1016/j.scitotenv.2020.138532 PMid:32304970

27. Ranney ML, Griffeth V, Jha AK. Critical supply shortages-the need for ventilators and personal protective equipment during the COVID-19 pandemic. N Engl J Med. 2020;382(18):e41. https://doi.org/10.1056/NEJMp2006141 PMid:32212516

28. Lobner E, Wachernig A, Gudipati V, Mayrhofer P, Salzer B Lehner M, et al. Getting CD19 into shape: Expression of natively folded "difficult-to- express" CD19 for staining and stimulation of CAR-T cells. Front Bioeng Biotechnol. 2020;8:49. https://doi. org/10.3389/fbioe.2020.00049 PMid:32117929

29. Foo C, Wai L, Lang T. The mind of a technopreneuress: Differentiating the self-leading, entrepreneurial from custodial, managerial female. Technovation. 2006;26(2):175-84.

30. Bulso R, Goncalves G, Leonardi T, Balbinotti C. Evaluation of technical-tactical performance in tennis: a systematic review of measurement instruments. Physical Education and Sport Notebook. 2020;18:57-62.

31. Halpern NA, Tan KS, DeWitt M, Pastores SM. Intensivists in US acute care hospitals. Crit Care Med. 2019;47(4):517-25. https:// doi.org/10.1097/CCM.0000000000003615

PMid:30694817

32. Halpern NA, Tan KS. United States resource availability for COVID-19. Soc Crit Care Med. 2020;1-16.

33. WHO. World Health Day-Global Brief. Geneva: WHO; 2012. Available from: https://www.who.int/world-health-day/2012/en [Last accessed on 2021 Aug 21]. 